Materials Sciences Division, Lawrence Berkeley National Laboratory, and

Department of Materials Science and Engineering

University of California at Berkeley

\title{
ON THE FRACTURE OF HUMAN DENTIN: IS IT STRESS- OR STRAIN-CONTROLLED?
}

\author{
R. K. Nalla ${ }^{1}$, J. H. Kinney ${ }^{2}$ and R. O. Ritchie ${ }^{1,3}$ \\ ${ }^{1}$ Materials Sciences Division, Lawrence Berkeley National Laboratory, and \\ Department of Materials Science and Engineering, \\ University of California, Berkeley, CA 94720 \\ 2 Department of Preventive and Restorative Dental Sciences, \\ University of California, San Francisco, CA 94143 \\ ${ }^{3}$ Corresponding author: Tel: (510) 486-5798; Fax: (510) 486-4881 \\ E-mail address: RORitchie@lbl.gov (R. O. Ritchie)
}

September 2002

revised January 2003

submitted to the Journal of Biomedical Materials Research

This work was supported in part by the National Institutes of Health, National Institute for Dental and Craniofacial Research under Grant No. P01DE09859. 


\title{
ON THE FRACTURE OF HUMAN DENTIN: IS IT STRESS- OR STRAIN-CONTROLLED?
}

\begin{abstract}
Despite substantial clinical interest in the fracture resistance of human dentin, there is little mechanistic information in archival literature that can be usefully used to model such fracture. In fact, although the fracture event in dentin, akin to other mineralized tissues like bone, is widely believed to be locally strain-controlled, there has never been any scientific proof to support this belief. The present study seeks to address this issue through the use of a novel set of in vitro experiments in Hank's Balanced Salt Solution involving a double-notch bend test geometry which is designed to discern whether the critical failure events involved in the onset of fracture are locally stress- or straincontrolled. Such experiments are further used to characterize the notion of "plasticity" in dentin and the interaction of cracks with the salient microstructural features. It is observed that fracture in dentin is indeed locally strain-controlled and that the presence of the dentinal tubules does not substantially affect this process of crack initiation and growth. The results presented are believed to be critical steps in the development of a micromechanical model for the fracture of human dentin that takes into consideration the influence of both the microstructure and the local failure mode.
\end{abstract}

Keywords: Dentin, fracture, double-notched bend test, fractography, microstructure.

\section{Introduction}

Dentin, the most abundant mineralized tissue in the human tooth, is located between the hard exterior enamel and the softer interior pulp. There is very limited understanding of its structural behavior, despite the fact that this is essential to the prediction of how microstructural alterations due to dentin pathologies and their treatment can degrade the strength and structural integrity of the tooth. Indeed, whereas there are some five decades of research on the mechanical properties of dentin [e.g.1-16], there is still little fundamental comprehension of some of the basic questions that dictate its structural 
behavior. Notable among these is how fracture occurs in dentin. In particular, no micromechanical model for the fracture of dentin, that incorporates a local fracture criterion with consideration of the role of the salient microstructural features, has ever been developed. Such a model is essential for the understanding of how microstructural alterations can influence the toughness of dentin and thus affect the useful life of the tooth.

To date, only a handful of quantitative studies have been reported in archival literature on the fracture toughness ${ }^{1}$ of human dentin. The earliest of these was by Rasmussen et al. $[10,11]$ who used a "work of fracture" (defined as the work per unit area to generate new crack surface) to quantify the resistance to fracture. Unfortunately, the work of fracture, so defined, can be highly dependent on the geometry and sample size. Therefore, the results reported cannot be compared quantitatively with any subsequent measurements. However, the their studies did suggest that the toughness varies with orientation. Specifically, the work of fracture tended to be lower for cracking perpendicular to the dentinal tubular direction, i.e., in the plane of the mineralized collagen fibrils, compared to all other directions. This suggests that crack bridging by the collagen fibrils could enhance the toughness along directions parallel to the tubule axes. Indeed, ref. [10] does indicate that crack propagation perpendicular to the tubules is more energetically favorable, consistent with the notion that there can be no fiber bridging in that direction, although the excessive scatter in their results make definitive conclusions difficult.

A subsequent study, by el Mowafy et al. [6], was the first to utilize fracture mechanics, using compact-tension specimens to measure the fracture toughness, $K_{\mathrm{c}}$, of dentin. For an orientation parallel to the long axis of the tubules, these authors reported a toughness of $K_{\mathrm{c}}=3.08 \mathrm{MPa} \sqrt{\mathrm{m}}$ (standard deviation $0.33 \mathrm{MPa} \sqrt{\mathrm{m}}$ ) for dentin, which was found to remain constant from $0^{\circ}$ to $60^{\circ} \mathrm{C}$. However, their experiments were carried out

\footnotetext{
${ }^{1}$ The fracture toughness is a fracture-mechanics based parameter that is used to describe the onset of fracture. For an elastic body, it is defined at fracture either in terms of a critical value of the strain-energy release rate, $G_{\mathrm{c}}$, defined as the change in potential energy per unit increase in crack area, or in terms of a critical value of the stress-intensity factor, $K_{\mathrm{c}}=Q \sigma_{\mathrm{app}}\left(\pi a_{c}\right)^{1 / 2}$, which characterizes the local stress and displacement fields ahead of a sharp crack ( $\sigma_{\text {app }}$ is the applied stress, $a_{\mathrm{c}}$ is the critical crack length, and $Q$ is a geometry factor of order unity). Under linear-elastic conditions for mode I (tensile opening) loading, $K_{\mathrm{c}}$ $=\left(E^{\prime} G_{\mathrm{c}}\right)^{1 / 2}$, where $E^{\prime}$ is the appropriate elastic modulus for plane stress or plane strain [20].
} 
on machined notches, rather than with atomically-sharp (e.g., fatigue) precracked samples, and it is well known for a wide variety of materials including metals, ceramics and composites (e.g., ref. [17-25]) that the presence of a notch of finite radius, rather than a sharp precrack, can lead to severe overestimates of the fracture toughness.

More recently, Iwamoto et al. [13] reported fracture toughness values and an effect of tubule orientation for human dentin, using the so-called notchless triangular prism specimen geometry. However, the accuracy of these data may be deemed to be somewhat questionable in light of the non-standard nature of the toughness test. Imbeni et al. [15], conversely, used fatigue-precracked three-point bend bar samples (nominally conforming to ASTM standards) in order to determine an accurate measure of the in vitro fracture toughness of human dentin and to further assess the influence of notch acuity on such results. Measurements, made in an orientation perpendicular to the tubules in order to determine a worst-case value, yielded a fracture toughness of $K_{\mathrm{c}}=1.79 \mathrm{MPa} \sqrt{\mathrm{m}}$ (std. dvn. 0.1). This value is considerably lower than the earlier el Mowafy et al. [6] result, consistent with Imbeni et al.'s observations [15] that toughness values are significantly increased with increasing root radius.

The aim of the present study is to gain a further understanding of the factors that contribute to the in vitro fracture properties in human dentin by discerning the nature of the microscopic local failure criteria for the onset of cracking and characterizing how the subsequent crack growth is affected by microstructure.

\section{Background}

Qualitatively, local fracture events that result in macroscopic fracture can be described as either locally stress- or strain-controlled. This is an important distinction in understanding the nature of fracture from a rounded notch or sharp crack (as in a toughness test), because in the presence of any degree of plastic deformation or ineleasticity, the maximum local strains are at the crack or notch tip whereas the maximum local stresses are ahead of the tip (Fig. 1).

For example, brittle fracture in metallic and ceramic materials, e.g., by cleavage cracking, is invariably modeled as (tensile) stress-controlled, involving the unstable propagation of a microcrack, initiated when the local tensile stresses exceed some critical 
local fracture stress [26]. Ahead of a sharp crack [27,28] or rounded notch [29,30], the probability of this local event occurring is generally highest at the location of maximum tensile (or hydrostatic) stress, which in the absence of yielding is at the crack or notch tip (e.g., as in ceramics). However, with inelastic deformation, some degree of blunting occurs at a crack tip such that the location of the maximum stresses [29,31], and hence the most probable site for the initiation of fracture [32,33], moves ahead of the tip (e.g., as in metals). The location of this site depends on several factors, including the applied stress intensity $K$, yield strength $\sigma_{\mathrm{y}}$, Young's modulus, $E^{\prime}$, and, in the case of a notch, its root radius or included angle. For a sharp crack, it is located at roughly two crack-tip opening displacements from the crack tip [31], i.e., at a distance on the order of $K^{2} / \sigma_{\mathrm{y}} E^{\prime}$ (for a general description, see refs. [34,35]); for a rounded notch, it is several orders of magnitude further away from the tip, essentially at, or just behind, the boundary of the plastic zone, i.e., at a distance on the order of $\left(K / \sigma_{\mathrm{y}}\right)^{2}$ [29,30]. Ductile fracture, conversely, has been modeled as locally strain-controlled, involving the initiation and coalescence of voids. Ahead of a sharp crack or rounded notch, this event is most likely to occur at the location of maximum equivalent strain, which is at the crack or notch tip [35-37].

From the foregoing discussion, it is apparent that for materials that display any degree of inelasticity, the location of the microstructural cracking events that precede the onset of macroscopic fracture ahead of a notch are a definitive indicator of whether the fracture is locally stress- or strain-controlled; strain-controlled fracture will initiate at the notch whereas stress-controlled will initiate ahead of the notch [33,35,37-46].

It should be noted here that the separation of the sites of peak tensile stress and plastic strain are the direct consequence of some degree of inelasticity "yielding" at the notch tip. In dentin, however, such yielding cannot be simply related to pure pressureinsensitive, shear-driven plasticity, as in metals, for which the notch-field solutions in Fig. 1 were explicitly derived. Although the precise nature of the inelastic constitutive behavior of dentin is not known, it clearly involves processes such as diffuse microcracking damage [e.g.,47,48], plasticity in the highly extendable, low-modulus collagen fibrils (which would be sensitive to both tensile and shear stresses, akin to pressure-dependent yielding in traditional polymeric materials), and poro-elasticity (due 
to the considerable fluid volume distributed in an open porous structure). Despite this, most theoretical models for both deformation and fracture [e.g.,49,50] in mineralised tissues such as dentin and bone simply utilize the von Mises criterion, which is based on pressure-insensitive plasticity theory. However, recent finite element results [51] for inelastic deformation by both pressure-insensitive plasticity and pressure-sensitive microcracking indicate that the notch stress and strain fields are qualitatively similar, i.e., the local stresses peak still ahead of a notch and the local strains peak at the notch root. It is in this spirit that we use the notch-field solutions, although it must be recognised that the precise quantitative details of these fields have yet to be determined for dentin.

Given this difference between the notch stress and strain distributions, the distinction between stress- or strain-controlled fracture can be achieved through the use of the double-notched four-point bend sample (Fig. 2), which has two important features to enable the evaluation [42-44,51-53]:

- Rounded notches with a large root radius section $(\rho>200 \mu \mathrm{m})$ are utilized (rather than sharp cracks) to maximize the difference between the locations of maximum stress and maximum strain ahead of the notch. Hill's well known logarithmic slipline field solution [29] for the notch in a perfectly-plastic solid (Fig. 1a) gives the location of the maximum tensile stress (and maximum degree of triaxiality) at the elastic-plastic interface. Subsequent finite-element solutions for a linear workhardening solid by Griffiths and Owen [30] show that this location is actually behind the elastic-plastic interface; depending on the nominal (far-field) applied stress, it is typically at distances of 0.7-3 times the notch root radius ahead of the notch (Fig. 1b). The maximum strains, conversely, are at the notch root and decrease monotonically with distance ahead of the notch [30].

- Two notches in four-point bending are employed because, as there is a constant bending moment between the inner two loading points, both notches see exactly the same stress- and strain-states. For a nominally brittle material, such as dentin, this means that when unstable fracture ensues from one notch, the other notch will be literally at the point of instability, thereby "freezing in" the local microstructural events that precede fracture. Examination of the microstructure below this unbroken 
notch thus enables an evaluation of how and where the critical cracking processes initiate, and in doing so define whether the process is stress- or strain-controlled.

It might be noted here that even though the actual measurement of the fracture toughness must involve fracture from a nominally atomically sharp crack, this particular experiment is best carried out with rounded notches because the distinction between the sites of the maximum tensile stress and strain substantially diminishes as the root radius, $\rho \rightarrow 0$ [2931].

Micromechanical models for fracture incorporating such local failure criteria have been widely developed for metallic systems, e.g., the so-called RKR model for stresscontrolled cleavage fracture [18] and the stress-state modified strain-controlled fracture model for ductile (microvoid coalescence) fracture [23-25]; however, such deliberations have not been undertaken for the fracture of biomaterials such as dentin ${ }^{2}$. This is somewhat surprising as the strain-based criteria have been widely used to model such materials, e.g., bone [e.g.,47,54,55]. Indeed, since dentin displays marked "yielding" and post-yield behavior, in the form of irrecoverable diffuse damage, as shown in Section 4.2, a strain-based fracture criteria would appear to be most probable, although none of this has ever been proven conclusively.

The prime objective of the current work is thus to utilize the philosophy described above to determine systematically the nature of the local fracture mechanisms in human dentin, using the double-notched bending test described above. In addition, the aim is to address several unanswered questions concerning the interaction of the crack with the microstructural features in dentin, specifically:

- whether the tubules actually affect the macroscopic crack path,

- the nature of the interaction as the crack tip encounters a tubule,

- the role of the mineralized peritubular dentinal cuff in enhancing the toughness [15].

It is believed that in addition to the mechanistic understanding gained, this work is of importance from a practical perspective. Notches resulting from natural caries, and possibly dental repair processes, are common in human teeth, and as such, a mechanistic

\footnotetext{
${ }^{2}$ Recent studies using the double-notch geometry have shown that fracture in human cortical bone is consistent with a strain-based criterion $[51,53]$.
} 
understanding of dentin fracture from such notches may be considered critical for development of a methodology for the prediction of tooth failures.

\section{Experimental Procedures}

\subsection{Material}

Recently extracted human molars, sterilized using gamma radiation after extraction [56], were used in the present study. Sections $(\sim 1.5-2.0 \mathrm{~mm}$ thick) were prepared from the central portion of the crown and the root vertically through the tooth. A typical microstructure of dentin is shown in Fig. 3, with the tubules being the most characteristic feature; this structure is described in more detail below in Section 4.1. Although specimens were cut in order to define a specific orientation of the microstructure with respect to the crack path, in actuality it is almost impossible a priori to align the fracture plane precisely with, for example, the tubule axes because, with the exception of the root, the tubules in dentin do not run a straight course from the enamel to the pulp. Rather, from the cervical margin through the crown, the tubules have a complex, S-shaped curvature [57]. This is well illustrated by the scanning electron micrograph in Fig. 4 showing the side of a notch and the fracture surface of the crack emanating from it; despite the fact that these two surfaces are mutually perpendicular, the orientation of the tubules appears to be identical on the two planes. Consequently, the orientation of the crack plane was determined from examination of the crack paths and the fracture surfaces.

Beams of dentin measuring roughly $1.0 \times 1.0 \times 12.0 \mathrm{~mm}$ were then obtained from these sections by carefully further sectioning using a slow-speed diamond saw and subsequent wet polishing up to a 600 grit finish. These beams were then stored in Hank's Balanced Salt Solution (HBSS) at ambient temperature. Although mineral can be leached into solution when storing dentin in deionized water, which can result in changes in elastic properties with storage time, no such changes could be detected following short time storage in HBSS [58]. However, the precise effects of storage solution on the fracture properties have not been investigated per se. 
In vitro first yield $\left(\sigma_{\mathrm{y}}\right)$ and maximum flexural $\left(\sigma_{\mathrm{F}}\right)$ strengths were measured in ambient-temperature HBSS in bending to be, respectively, $\sigma_{\mathrm{y}} \sim 75 \mathrm{MPa}$ and $\sigma_{\mathrm{F}} \sim 160$ MPa. A typical in vitro load-displacement curve is shown in Fig. 5. Macroscopically, there is clear evidence of "yielding", akin to that observed commonly in many metallic systems. As noted above, it is believed that such inelasticity is the result of irrecoverable diffuse microdamage induced during loading, similar to that reported for trabecular bone [47]; this issue is addressed in more detail in Section 4.2.

\subsection{Mechanical testing}

Tests were conducted in HBSS using a symmetric four-point (pure) bending geometry with a double rounded-notched configuration (Fig. 2a), as described above; this sample creates a constant bending moment between the inner two loading points, which in the present tests had a span $S$ equal to 2-4 times the width $W$ of the beam. Rounded notches, of root radius, $\rho \sim 200-300 \mu \mathrm{m}$, and depth, $a \sim 0.3-0.4 \mathrm{~W}$, were introduced carefully with a slow-speed saw; care was taken to maintain the specimens in a hydrated state throughout the specimen preparation process. The depths of both notches in each specimen were kept as identical as possible in order to ensure similar stress/strain fields at the notch tips. A total of ten such tests were conducted. Conditions can be considered to be nominally plane strain as, in accordance with the ASTM Standard E-399 for fracture toughness testing, the thickness of the bend specimens was comparable with 2.5 $\left(K_{\mathrm{c}} / \sigma_{\mathrm{y}}\right)^{2}(\sim 1.4 \mathrm{~mm})$.

All testing was conducted at ambient temperature on an $\operatorname{ELF}^{\circledR} 3200$ series voice coilbased mechanical testing machine (EnduraTEC Inc., Minnetonka, MN). The bend bars were loaded to failure under displacement control at a constant cross-head movement rate of $0.02 \mathrm{~mm} / \mathrm{min}$ in $\mathrm{HBSS}$ at $25^{\circ} \mathrm{C}$.

\subsection{Microstructural characterization}

The area around the unfractured notch in the fractured double-notched samples was examined using a high-power optical microscope and (after coating with a goldpalladium alloy) with a scanning electron microscope (SEM) operating in the back- 
scattered electron mode. To minimize the possibility of any damage during specimen preparation, the dentin beams were kept hydrated during all preparation and testing procedures, and for SEM imaging until the actual coating was performed. Moreover, given the further possibility of dehydration-induced cracking during the SEM imaging itself, some specimens were first observed in a hydrated condition in an environmental SEM and an atomic-force microscope to verify that the cracking configurations observed were not artifacts of the experimental procedure. The micrographs presented in this paper, however, were obtained from a conventional SEM as this provided the maximum resolution. Additionally, post-failure observations of the fracture surfaces of the broken ligaments were carried out using the same techniques.

\section{Results and Discussion}

\subsection{Microstructure of dentin}

Human dentin is a hydrated composite of nanocrystalline carbonated apatite mineral ( $\sim 5 \%$ by volume), type-I collagen fibrils $(\sim 30 \%$ by volume) and fluid ( $\sim 25 \%$ by volume). The mineral component is distributed in the form of $5 \mathrm{~nm}$ thick crystallites in a scaffold created by the fibrils (typically 50-100 nm diameter). The most distinctive feature of this "microstructure" is a unique distribution of 1-2 $\mu \mathrm{m}$ diameter cylindrical tubules (Fig. 3) that run from the dentin-enamel junction (DEJ) to the soft pulp in the interior of the tooth. These dentinal tubules are actually the paths of the odontoblast cells during tooth formation. They are surrounded by a collar of highly mineralized peritubular dentin ( $\sim 1 \mu \mathrm{m}$ thick) and are embedded within a matrix of mineralized collagen (intertubular dentin). The mineralized collagen fibrils form a planar felt-like structure oriented perpendicular to the tubules [59]. The tubules are randomly displaced about a periodic lattice [60], but with a distribution that depends on location within the tooth [e.g., 8]. The interaction of these tubules with cracks in the dentin is of obvious interest from the perspective of an understanding of the failure of dentin; this issue is addressed in Section 4.3.

\subsection{Inelasticity or "yielding" in dentin}


Since the concept of the double-notched four-point bend test to distinguish between stress- and strain-controlled fracture is based on the premise of inelasticity or plastic yielding, it is important to establish that inelastic deformation does indeed occur in human dentin. Although such deformation is well understood for traditional materials e.g., in the form of dislocation activity in metals, the mechanism of "yielding" in dentin is far less characterized, but can be considered in terms of regions of "diffuse microdamage", as in bone [e.g.,47]. Moreover, the nonlinear, non-recoverable nature of the load/displacement curve measured for dentin in the current work (Fig. 5) is indicative that some form of "plastic" yielding does indeed occur.

With respect to localized yielding in the presence of cracks, the notion of a plastic zone is invariably used, where the stresses locally exceed the "yield" strength, $\sigma_{y}$, of the material. The plastic-zone size can be roughly estimated from continuum arguments [e.g.,34] to scale with the square of the ratio of the fracture toughness to the "yield" strength; specifically, at the onset of fracture, the maximum dimension is approximately $r_{\mathrm{y}} \sim 1 / 2 \pi\left(K_{\mathrm{c}} / \sigma_{\mathrm{y}}\right)^{2}$, which in dentin is on the order of $100 \mu \mathrm{m} .^{3} \quad$ The boundary of this zone is drawn around a typical crack in human dentin in Fig. 6a. It is evident that within this zone (Figs. 6c,d), "microdamage" can be seen in the form of cracked dentinal tubule cuffs, whereas no such damage is apparent outside the zone (Fig. 6b). Thus, the existence of a nonlinear load/displacement curve and formation of a "microdamage" zone in the high-stress regions surrounding a crack are strong evidence that dentin does display inelastic deformation, consistent with the notion of diffuse microcracking of the peritubular cuffs.

\subsection{Double-notch experiments}

Results from the double-notched four-point bend tests, which were used to detect the microstructural events prior to macroscopic fracture in dentin specimens, are shown in the macroscopic images in Fig. 7, before and after failure at one of the notches, and in the microscopic SEM images of the crack paths in Figs. 8-9. Macroscopic and microscopic

\footnotetext{
${ }^{3}$ Note that the relationship used to estimate the plastic-zone size, $r_{\mathrm{y}} \sim 1 / 2 \pi\left(K_{\mathrm{c}} / \sigma_{\mathrm{y}}\right)^{2}$, pertains roughly to the maximum extent of the zone in plane strain and the forward extent in plane stress. It is thus a reasonable approximation for all stress-states.
} 
images of the fracture surfaces are shown in Fig. 10. As described above, when one notch breaks, the other is "frozen" at a point immediately preceding unstable fracture. Examination in the scanning electron microscope of this region, marked by the white circle in Fig. 7b, clearly indicates that all precursor cracks form directly at the notch root, generally with evidence of multiple initiation, as shown in Fig. 8. To provide absolute proof that these cracks actually formed at the notch, serial sectioning should be used, although this was not feasible with the present samples as they were so fragile. However, the extremely small $(<10 \mu \mathrm{m})$ size of the precursor cracks that are imaged (e.g., Fig. 9 where a $\sim 2-3 \mu \mathrm{m}$ crack can be seen at the notch root surface) leaves little doubt that crack initiation is at the notch and not ahead of it.

For the specimens tested, the nominal elastic bending stress, $\sigma_{\text {nom, }}$, at the notch tip at maximum load was in the $50-95 \mathrm{MPa}$ range $\left(\sigma_{\mathrm{nom}} / \sigma_{\mathrm{y}}=0.67-1.27\right)$. According to the numerical analysis of Griffiths and Owen [30], the maximum tensile stress, $\sigma_{11}$, occurs at $\sim 140$ to $330 \mu \mathrm{m}$ ahead of the notch tip, i.e., roughly at a distance of $0.7-1.1$ times the notch root radius. As absolutely no evidence of precursor cracking was found in this region and all cracking was detected exactly at the notch root, we can conclude that fracture in human dentin is indeed consistent with a locally strain-based criteria.

\subsection{Microstructure/crack path interactions}

Scanning electron micrographs of the subsequent propagation of the crack and its interaction with the salient microstructural features in human dentin are shown in Figs. 11 and 12. Fig. 11 shows scanning electron micrographs of one such crack, which has propagated some $200 \mu \mathrm{m}$ from the notch. The plane of the crack and the crack front can be seen to be nominally parallel to the axis of the tubules, which are spaced roughly 10

$\mu \mathrm{m}$ apart. It is evident that at this scale of observation, the crack path is relatively deflection free, implying that the most recognizable feature of the microstructure, i.e., the tubules, do not have a major influence on the fracture process or the path taken by the growing crack. As noted above, there is, however, ample evidence of damage in the form of cracking of the peritubular dentin cuff for the tubules in the vicinity of the growing crack, as indicated by the arrows and the insets in Fig. 11. As these sub-cracks form 
ahead of the main crack tip (Fig. 11c), using the arguments outlined above, their formation may be presumed to be stress-controlled. Where these cracked peritubular cuffs are within a few micrometers of the main crack path, minor out-of-path deflections can be seen (Fig. 11c). However, in general, since the crack path neither seeks out, nor avoids, these regions, as indicated by the high magnification SEM micrographs in Fig. 12 , it would appear that the role of the cracked peritubular cuffs or tubules themselves is minimal in influencing the fracture process or toughening of human dentin.

These observations imply that the tubules may not, as has previously been suggested, play a causative role in the reported anisotropy in the mechanical properties of human dentin [e.g.,10,11,13]. Although not specifically examined in the present work, it is more likely that such anisotropy results from the orientation of the collagen fibril network (which may act to "bridge" the crack), as has been suggested for bone [e.g.,51,53,61,62], and more importantly from crack bridging due to the formation of uncracked ligaments [63]. It should be noted that investigations into such effects (see refs. [15,63] for further discussion) yielded a $6 \%$ higher "notch" toughness for an orientation where the long axis of the tubules was in the plane of crack propagation (perpendicular to the direction of propagation), as compared to an orientation with the long axes perpendicular to both the plane and direction of crack propagation. Such results are consistent with a contribution to the toughness from crack bridging by the collagen fibrils and uncracked ligaments, as discussed in detail elsewhere [63].

\section{Conclusions}

Based on an experimental study of the in vitro fracture behavior of human dentin (at $25^{\circ} \mathrm{C}$ in Hank's Balanced Salt Solution), specifically to examine the character of the deformation, local fracture mechanisms and the role of the principal microstructural features in influencing the process of crack initiation and growth, the following conclusions can be made:

1. Through the use of double-notched four-point bend testing to determine the location (in relation to the notch) and nature of the microstructural cracking events 
immediately prior to failure, fracture in human dentin has been shown to be consistent with a locally strain-controlled failure criterion.

2. Metallographic examination of a growing crack in dentin revealed the existence of a "microdamage" zone ahead, and in the wake of, the crack tip; the size of this zone was comparable with continuum estimates for the plastic-zone size, based on the "yield" strength of dentin. Within this zone, extensive evidence of microcracking of the dentinal tubule cuffs was apparent, consistent with the notion that "plasticity" in dentin involves some form of "diffuse microdamage".

3. Examination of the subsequent crack growth revealed only minimal interaction of crack with the presence and orientation of the tubules or the existence of cracked peritubular cuffs. It is concluded that the mild influence of orientation reported for the fracture toughness of human dentin is not associated with the tubules per se, but more probably with the mineralized collagen fibrils that form a planar felt-like structure perpendicular to the tubule axes.

\section{Acknowledgments}

This work was supported in part by the National Institutes of Health, National Institute for Dental and Craniofacial Research under Grant No. P01DE09859. The authors wish to thank Profs. S. M. and G.W. Marshall of the Department of Preventive and Restorative Dental Sciences, University of California, San Francisco, CA for their active support, Ms. G. Nonomura for assistance with specimen preparation, Dr. V. Imbeni for the loaddisplacement data, and Drs. A. P. Tomsia and Imbeni for helpful discussions.

\section{References}

1. Craig RG, Peyton FA. Elastic and mechanical properties of human dentin. J Dent Res 1958;37:710-718.

2. Lehman ML. Tensile strength of human dentin. J Dent Res 1967;46:197-201. 
3. Cooper WE, Smith DC. Determination of shear strength of enamel and dentin. J Dent Res 1968;47:997p.

4. Renson CE, Boyde A, Jones SJ. Scanning electron microscopy of human dentin specimens fractured in bend and torsion tests. Arch Oral Biol 1974;19:447-457.

5. Renson CE, Braden M. Experimental determination of rigidity modulus, Poisson's ratio and elastic limit in shear of human dentin. Arch Oral Biol 1975;20:43-47.

6. el Mowafy OM, Watts DC. Fracture toughness of human dentin. J Dent Res 1986;65:677-681.

7. Balooch M, Wu-Magidi IC, Balazs A, Lundkvist AS, Marshall SJ, Marshall GW, Brekhaus WJ, Kinney JH. Viscoelastic properties of dimineralized human dentin measured in water with atomic force microscope (AFM)-based indentation. $\mathrm{J}$ Biomed Mater Res 1998;40:539-544.

8. Povolo F, Hermida EB. Measurement of the elastic modulus of dental pieces. J. Alloys Compounds 2000;310:392-395.

9. Balooch M, Demos SG, Kinney JH, Marshall GW, Balooch G, Marshall SJ. Local mechanical and optical properties of normal and transparent root dentin. J Mater Sci: Mater Medicine 2001;12:507-514.

10. Rasmussen ST, Patchin RE, Scott DB, Heuer AH. Fracture properties of human enamel and dentin. J Dent Res 1976;55:154-164.

11. Rasmussen ST, Patchin RE. Fracture properties of human enamel and dentin in an aqueous environment. J Dent Res 1984;63:1362-1368. 
12. Kinney JH, Balooch M, Marshall SJ, Marshall GW, Weihs TP. Hardness and young's modulus of human peritubular and intertubular dentin. Arch Oral Biol 1996;41:9-13.

13. Iwamoto N, Ruse ND. NTP specimen fracture toughness test applied to human dentin. In: Proc. SEM Annual Conf. and Exposition on Experimental and Applied Mechanics. Portland OR; 2001. p. 90-91.

14. Watanabe L, Marshall SJ, Marshall GW. Dentin shear strength: Effects of tubule orientation and intratooth location. Dent Mater 1996;12:109-115.

15. Imbeni V, Nalla RK, Bosi C, Kinney JH, Ritchie RO. On the in vitro fracture toughness of human dentin. J Biomed Mater Res 2003. in press.

16. Nalla RK, Imbeni V, Kinney JH, Staninec M, Marshall SJ, Ritchie RO. On the in vitro fatigue behavior of human dentin with applications for life prediction. $\mathrm{J}$ Biomed Mater Res 2003. in press.

17. Wilshaw TR, Rau CA, Tetelman AS. A general model to predict the elastic-plastic stress distribution and fracture strength of notched bars in plane strain bending. Eng Fract Mech 1968;1:191-211.

18. Spink GM, Worthington PJ, Heald PT. Effect of notch acuity on fracture toughness testing. Mater Sci Eng 1973;11:113-117.

19. Ritchie RO, Francis B, Server WL. Evaluation of toughness in AISI 4340 alloy-steel austenitized at low and high-temperatures. Metall Trans A 1976;7A:831-838.

20. Yokobori T, Kamei A, Konosu S. Criterion for low-stress brittle-fracture of notched specimens based on combined microfracture and macro fracture mechanics. I. Eng Fract Mech 1976;8:397-406. 
21. Datta, KP. Sharp crack and blunt notch toughness behavior of quenched and tempered AISI 4340 steel. Mater Sci Eng 1981;51:241-252.

22. Dauskardt RH, Ritchie RO, Takemoto JK, Brendzel AM. Cyclic fatigue and fracture in pyrolytic carbon-coated graphite mechanical heart-valve prostheses: Role of small cracks in life prediction. J Biomed Mater Res 1994;28:791-804.

23. Lowhaphandu P, Ludrosky LA, Montgomery SL, Lewandowski JJ. Deformation and fracture toughness of a bulk amorphous $\mathrm{Zr}-\mathrm{Ti}-\mathrm{Ni}-\mathrm{Cu}-\mathrm{Be}$ alloy. Intermetallics 2000;8:487492.

24. Lewandowski JJ. Effects of annealing and changes in stress state on fracture toughness of bulk metallic glass. Mater Trans- JIM 2001;42:633-637.

25. Manoharan M, Lewandowski JJ. Effect of microstructure and notch root radius on fracture-toughness of an aluminum metal matrix composite. Int J Fract 1989;40:R31R34.

26. Orowan E. Fracture and strength of solids. Rep Progr Phys 1948-9;12:185-232.

27. Hutchinson JW. Singular behavior at end of a tensile crack in a hardening material. J Mech Phys Solids 1968;16:13-31.

28. Rice JR, Rosengren GR. Plane strain deformation near a crack tip in a power-law hardening material. J Mech Phys Solids 1968;16:1.

29. Hill R. The Mathematical Theory of Plasticity. Oxford, U.K.: Clarendon Press; 1950.

30. Griffiths JR, Owen DRJ. An elastic-plastic stress analysis for a notched bar in plane strain bending. J Mech Phys Solids 1971;19:419-431.

31. Rice JR, Johnson MA. In: Kanninen MA et al. editors. Inelastic behavior of solids. New York, NY: McGraw Hill; 1970. 
32. Ritchie RO, Knott JF, Rice JR. On the relationship between critical tensile stress and fracture toughness in mild steel. J Mech Phys Solids 1973;21:395-410.

33. Lin T, Evans AG, Ritchie RO. Statistical analysis of cleavage fracture ahead of sharp cracks and rounded notches. Acta Metall 1986;34:2205-2216.

34. Knott JF. Fundamentals of fracture mechanics, London, U.K.: Butterworth \& Co. (Publishers) Ltd; 1976.

35. Ritchie RO, Thompson AW. On macroscopic and microscopic analyses for crack initiation and crack growth toughness in ductile alloys. Metall Trans A 1985;16A:233-248.

36. McClintock FA. J Appl Mech Trans ASME Ser H 1958;25:363.

37. Mackenzie AC, Hancock JW, Brown DK. On the influence of state of stress on ductile failure initiation in high strength steels. Eng Fract Mech 1977;9:167-188.

38. Ritchie RO, Horn RM. Further considerations on the inconsistency in toughness evaluation of AISI 4340 steel austenitized at increasing temperatures. Metall Trans A 1978;9A:331-341.

39. Ritchie RO, Server WL, Wullaert RA. Critical fracture stress and fracture strain models for the prediction of lower and upper shelf toughness in nuclear pressure vessel steels. Metall Trans A 1979;10A:1557-1570.

40. Lewandowski JJ, Thompson AW. Microstructural effects on the cleavage fracture stress in fully pearlitic 1080 steel. In: Valluri SR et al. editors. Advances in Fracture Research '84: Proc. $6^{\text {th }}$ Int. Conf. on Fracture (ICF-6). New Delhi India; 1984. p. $1515-1522$. 
41. Lewandowski JJ, Knott JF. Microstructural effects in flow localization in 7XXX Al alloys. Strength of Metals and Alloys - ICSMA 7. New York, NY: Pergamon Press; 1985. Vol. 2: p. 1193-1200.

42. Lewandowski JJ, Thompson AW. Microstructural control of the cleavage fracture stress in fully pearlitic steel. Metall Trans A 1986;17A:1769-1786.

43. Lewandowski JJ, Hippsley CA, Ellis MBD, Knott JF. Impurity effects on sustained load cracking of 21/4Cr-1Mo steels: 1 Crack initiation. Acta Metall 1987;35:593-609.

44. Lewandowski JJ, Hippsley CA. The nucleation of high temperature brittle intergranular fracture in 2¹/4Cr-1Mo steel. Metall Trans A 1988;19A:3005-3011.

45. Chu WY, Thompson AW. Hydrogen effects on brittle fracture of the titanium aluminide alloy Ti-24Al-11Nb. Metall Trans A 1992;23A:1299-1312.

46. Samant A, Lewandowski JJ. Effects of test temperature, grain size, and alloy additions on the cleavage fracture stress of polycrystalline niobium. Metall Trans A 1997;28A:389-99.

47. Yeh OC, Keaveny TM. Relative roles of microdamage and microfracture in the mechanical behavior of trabecular bone. J Orthopaedic Res 2001;19:1001-1007.

48. Vashishth D, Koontz J, Qiu S, Lundin-Cannon D, Yeni Y, Schaffler M, Fyhrie D. In vivo diffuse damage in human vertebral trabecular bone. Bone 2000;26:147-152.

49. Zioupos P, Currey JD, Mirza MS, Barton DC. Experimentally determined microcracking around a circular hole in a flat plate of bone: Comparison with predicted stresses. Philos Trans R Soc Lond B Biol Sci 1995;347:383-396.

50. Lotz JC, Cheal EJ, Hayes WC. Fracture prediction for the proximal femur using finite element models: Part I-Linear analysis. J Biomech Eng 1991;113:353-360. 
51. Nalla RK, Stölken, JS, Kinney JH, Ritchie RO. On the micro-mechanisms of in vitro fracture and toughening in human cortical bone. J Biomech 2003. in review.

52. Knott JF. Application of fracture mechanics to an alloy steel used in turbo-generator low-pressure disks. J Iron Steel Institute 1966;201:1014-121.

53. Nalla RK, Kinney JH, Ritchie RO. Mechanistic criteria for the failure of human cortical bone. Nature Matls 2003. in press.

54. Keaveny TM, Wachtel EF, Ford CM, Hayes WC. Differences between the tensile and compressive strengths of bovine tibial trabecular bone depends on modulus. $\mathrm{J}$ Biomech 1994;27:1137-1146.

55. Ford CM, Keaveny TM. The dependence of shear failure properties of trabecular bone on apparent density and trabecular orientation. J Biomech 1996;29:1309-1317.

56. White JM, Goodis HE, Marshall SJ, Marshall GW. Sterilization of teeth by gamma radiation. J Dent Res 1994;73:1560-1567.

57. Ten Cate AR. Oral Histology-Development, Structure and Function. $4^{\text {th }}$ edition, St. Louis, MO: Mosby (Publishers) 1994. p.173.

58. Habelitz S, Marshall GW, Balooch M, Marshall SJ. Nanoindentation and the storage of teeth. J Biomech 2002;35:995-998.

59. Jones SJ, Boyde A. Ultrastructure of dentin and dentinogenesis. In: Linde. editor. Dentin and dentinogenesis. Boca Raton, FL: CRC Press; 1984. 1(of 2): p 81-134.

60. Kinney JH, Oliveira J, Haupt DL, Marshall GW, Marshall SJ. The spatial arrangement of tubules in human dentin. J Mater Sci: Mater Medicine 2001;12:743751. 
61. Yeni YN, Fyhrie DP. Collagen-bridged microcrack model for cortical bone tensile strength. In: Proceedings of the 2001 Summer Bioengineering Conference,. New York, NY: ASME; 2001. BED-Vol. 50: p 293-294.

62. Kinney JH, Marshall SJ, Marshall GW. The mechanical properties of human dentin: A critical review and reevaluation of the dental literature. Crit Reviews Oral Biol Medicine 2003. in press.

63. Nalla RK, Kinney JH, Ritchie RO. Effect of orientation on the in vitro fracture toughness of dentin: The role of toughening mechanisms. Biomater 2003. in review. 


\section{LIST OF FIGURES}

Fig. 1: (a) Hill's logarithmic spiral slip-line field for a rounded notch in an elastic-plastic material [29], and the (b) tensile stress, $\sigma_{11}$, and (c) plastic strain, $\varepsilon_{11}$, distributions, based on slip-line field analysis [29] and numerical computations [30], ahead of such a notch. Also shown are schematic illustrations of possible (b) stress-controlled and (c) straincontrolled fracture mechanisms emanating from such notches. Note for stress-controlled mechanisms, the initial fracture event is ahead of the notch, whereas it is at the notch root for strain-controlled mechanisms.

Fig. 2: (a) Schematic illustration of the double-notched four-point bend test used to discern whether fracture is stress- or strain-controlled. Between the inner two loading points, the bending moment is constant; thus, when one notch breaks, the other is "frozen" at a point just prior to fracture instability. The region beneath this unbroken notch (as indicated in (b)) is then carefully examined to determine the site of the precursor microscopic events involved in the fracture process.

Fig. 3: A scanning electron micrograph of the typical "microstructure" of human dentin. The tubules that are the characteristic feature of the microstructure are evident.

Fig. 4: Scanning electron micrograph of the fracture surface (left-side) and the side of a failed notch (right-side), showing the strikingly similar orientation of the tubules on the two mutually perpendicular surfaces. 
Fig. 5: A typical load-displacement curve for human dentin tested in cantilever bending in HBSS solution at $25^{\circ} \mathrm{C}$. Note the apparent "yielding" and post-yield behavior.

Fig. 6: Scanning electron micrographs of the concept of a "yielding" or "damage" zone is shown, based on the regions where the peritubular cuffs are cracked. (a) An overview of a crack emanating from a notch, with the nominal damage zone indicated as a dotted line based on the continuum solution for the "plastic-zone" size (see text), and high magnification micrographs of areas (b) outside the zone, (c) inside the zone and (d) at the notch tip. Note the extensive cracking of peritubular cuffs in the "damage zone" in (c) and (d) (indicated by white arrows).

Fig. 7: Optical microscope images of the double-notched four-point bend specimen (a) before, and (b) after fracture. The critical area of interest, indicated by the white circle in (b), is in the region beneath the unbroken notch.

Fig. 8: Scanning electron micrographs of the microscopic cracking events immediately prior to unstable fracture in a double-notched four-point bend test, showing micron-scale cracks emerging from the root of the unbroken notch. Multiple initiation sites are evident in (b). The fact that these precursor cracks form at the notch, as opposed to a few hundred micrometers ahead of it, is definitive proof that fracture in dentin is locally strain-controlled. 
Fig. 9: A scanning electron micrograph of a 1-2 $\mu \mathrm{m}$ precursor crack initiating at the root of the unbroken notch in a double-notched four-point bend test.

Fig. 10: (a) A low-magnification scanning electron micrograph of the broken notch in a double-notched four-point bend test. The white arrow indicates the nominal direction of crack growth. (b) A high-magnification scanning electron micrograph of the morphology of the resulting fracture surface.

Fig. 11: Scanning electron micrographs of a $\sim 200 \mu \mathrm{m}$ crack emanating from the notch, showing the relationship between the crack path with the salient microstructural features. Insets in (b) and (c) show higher magnification images of the cracking of the peritubular cuffs (also shown by the white arrows in (a)) and the interaction of the sub-cracks with the main crack path.

Fig. 12: High-magnification scanning electron micrographs of the specific interaction of the tip of the main crack with (a) a tubule and (b) region of microdamage (indicated by white arrows) ahead of a crack tip. 
(a)
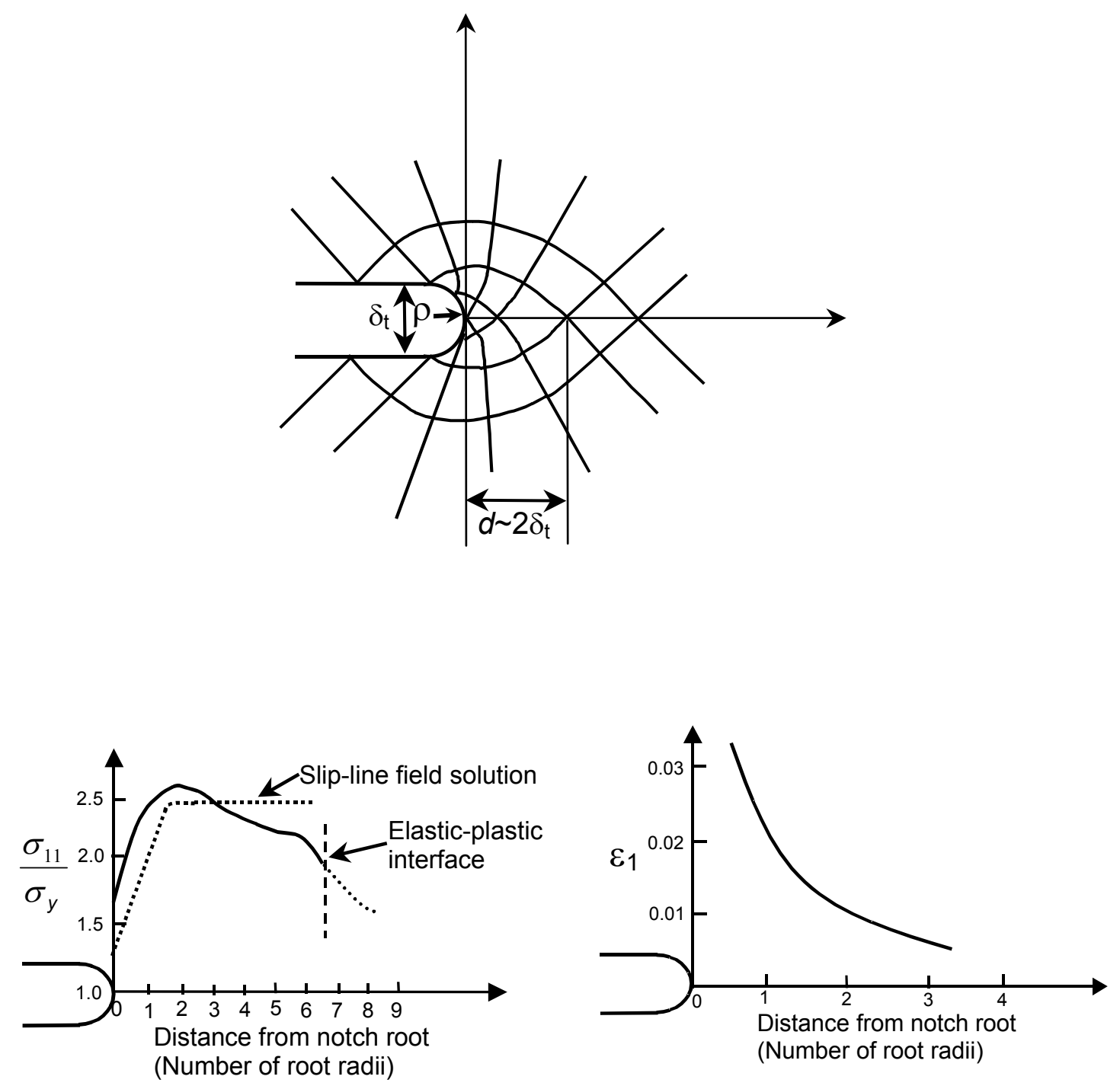

(b)

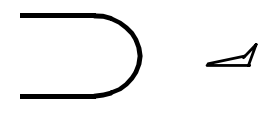

(c)

Figure 1: (a) Hill's logarithmic spiral slip-line field for a rounded notch in an elastic-plastic material [19], and the (b) stress and (c) strain distributions, based on slip-line field analysis [19] and numerical computations [22], ahead of such a notch. Also shown are schematic illustrations of possible (b) stress-controlled and (c) strain-controlled fracture mechanisms emanating from such notches. Note for stress-controlled mechanisms, the initial fracture event is ahead of the notch, whereas it is at the notch root for strain-controlled mechanisms. 


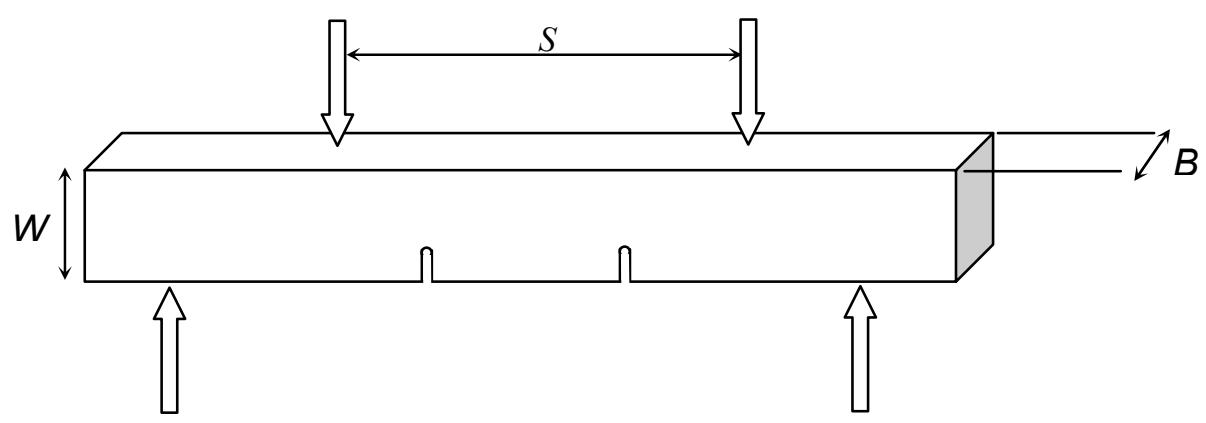

(a)

(b)

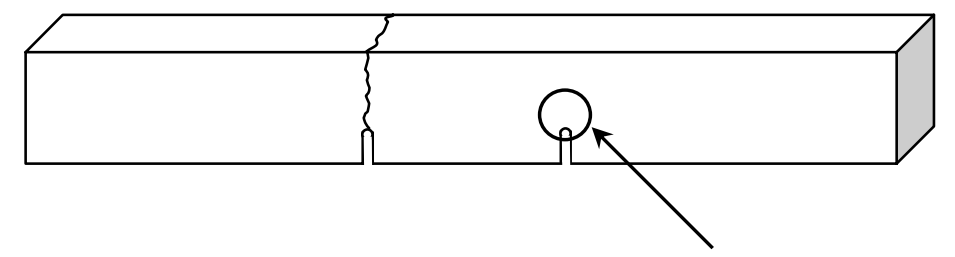

Figure 2: (a) Schematic illustration of the double-notched four-point bend test used to discern whether fracture is stress- or strain-controlled. Between the inner two loading points, the bending moment is constant; thus, when one notch breaks, the other is "frozen" at a point just prior to fracture instability. The region beneath this unbroken notch (as indicated in (b)) is then carefully examined to determine the site of the precursor microscopic events involved in the fracture process. 


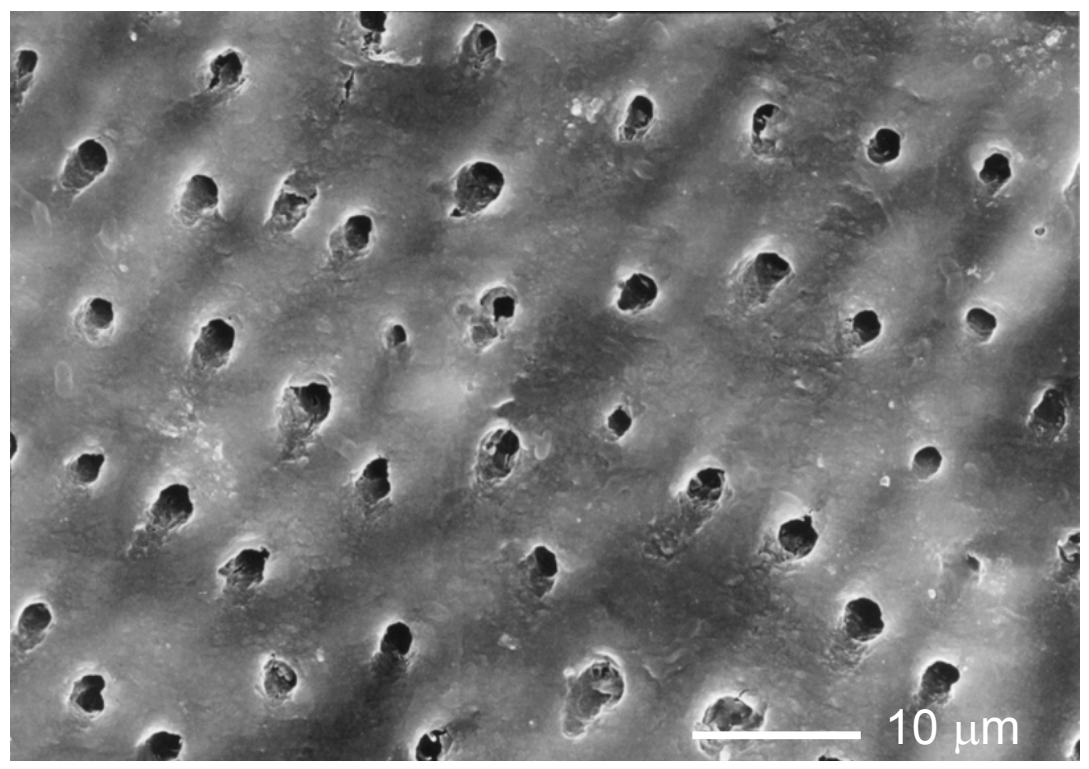

Figure 3: A scanning electron micrograph of the typical "microstructure" of human dentin. The tubules that are the characteristic feature of the microstructure are evident. 


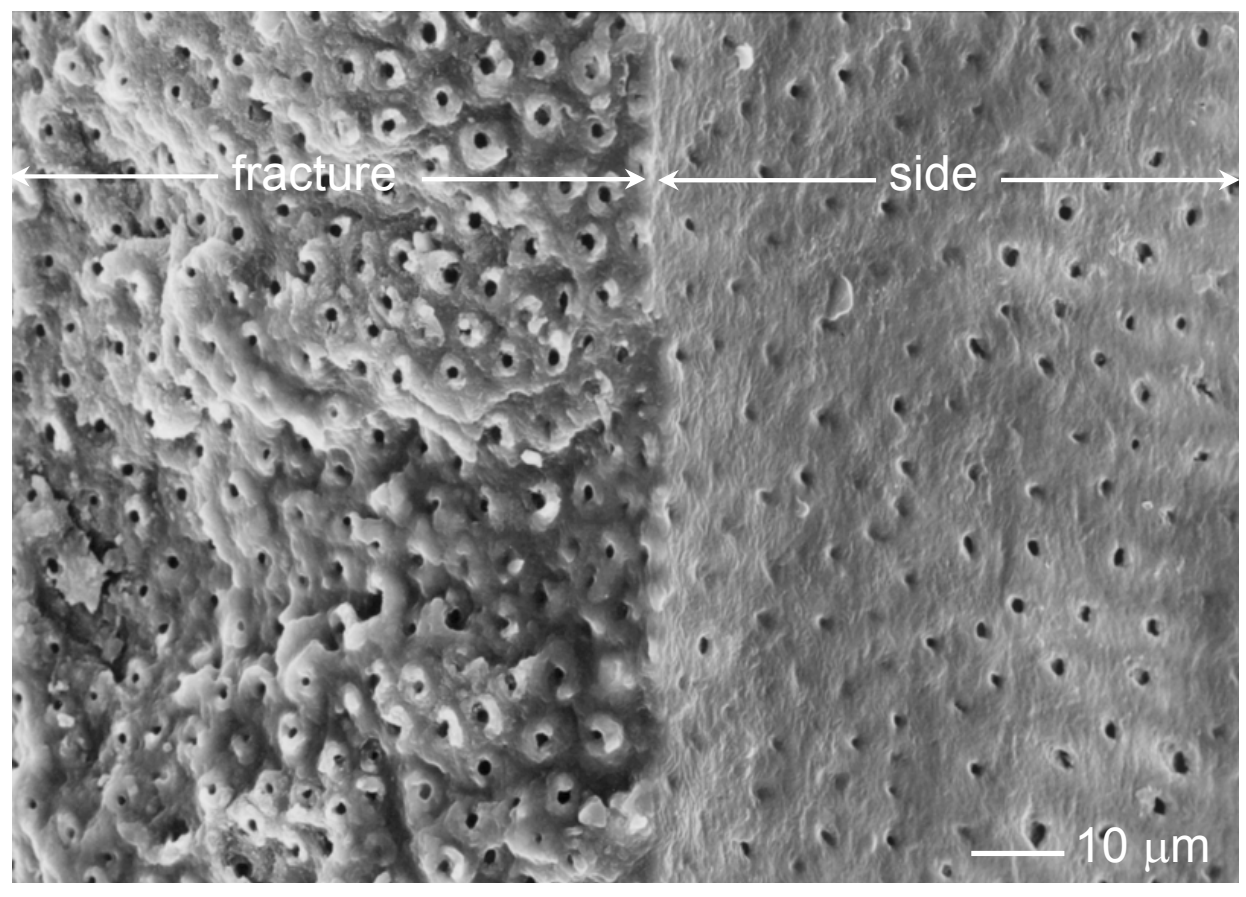

Figure 4: Scanning electron micrograph of the fracture surface (left-side) and the side of a failed notch (right-side), showing the strikingly similar orientation of the tubules on the two mutually perpendicular surfaces. 


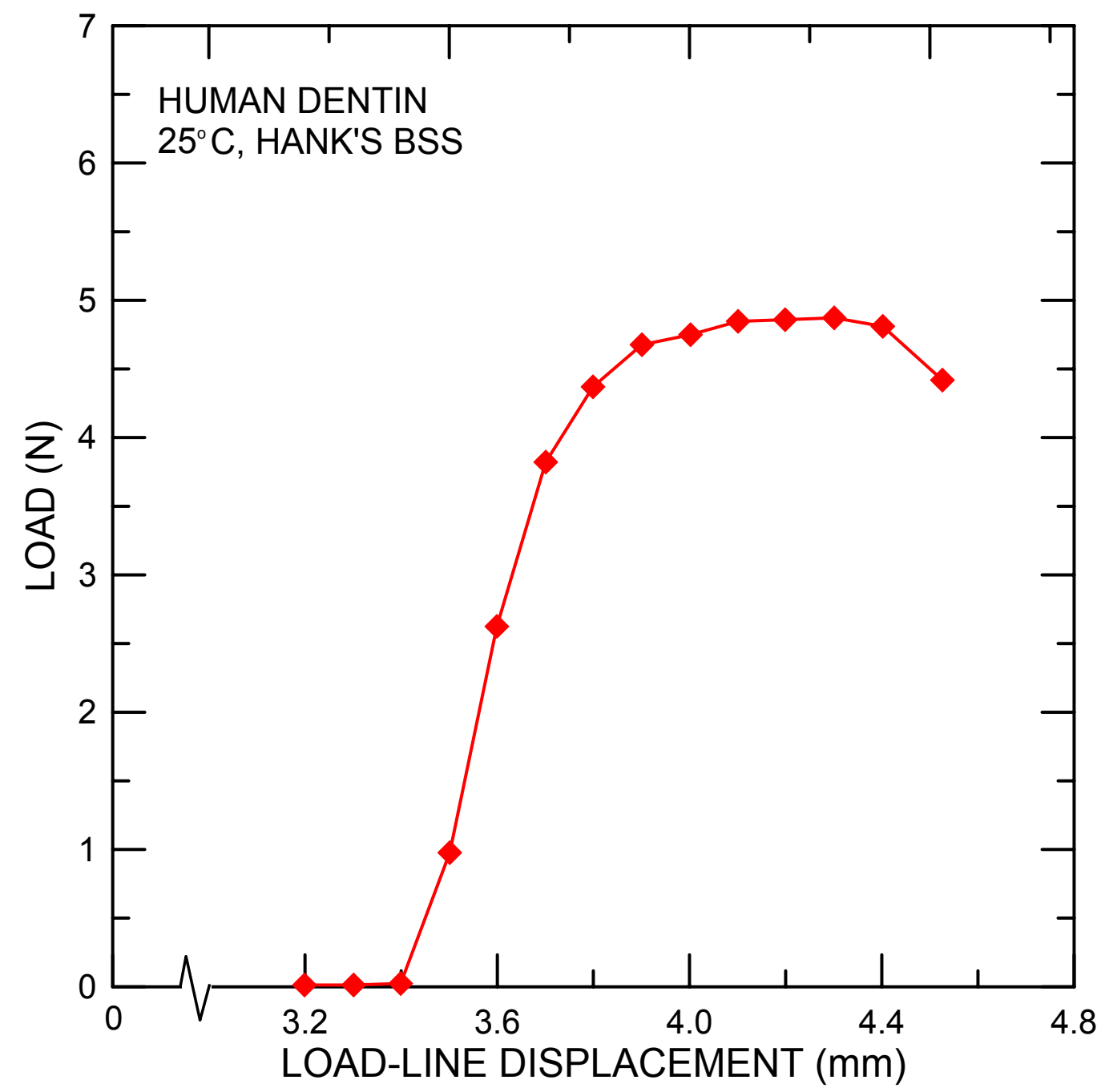

Figure 5: A typical load-displacement curve for human dentin tested in cantilever bending in HBSS solution at $25^{\circ} \mathrm{C}$. Note the apparent "yielding" and post-yield behavior. 


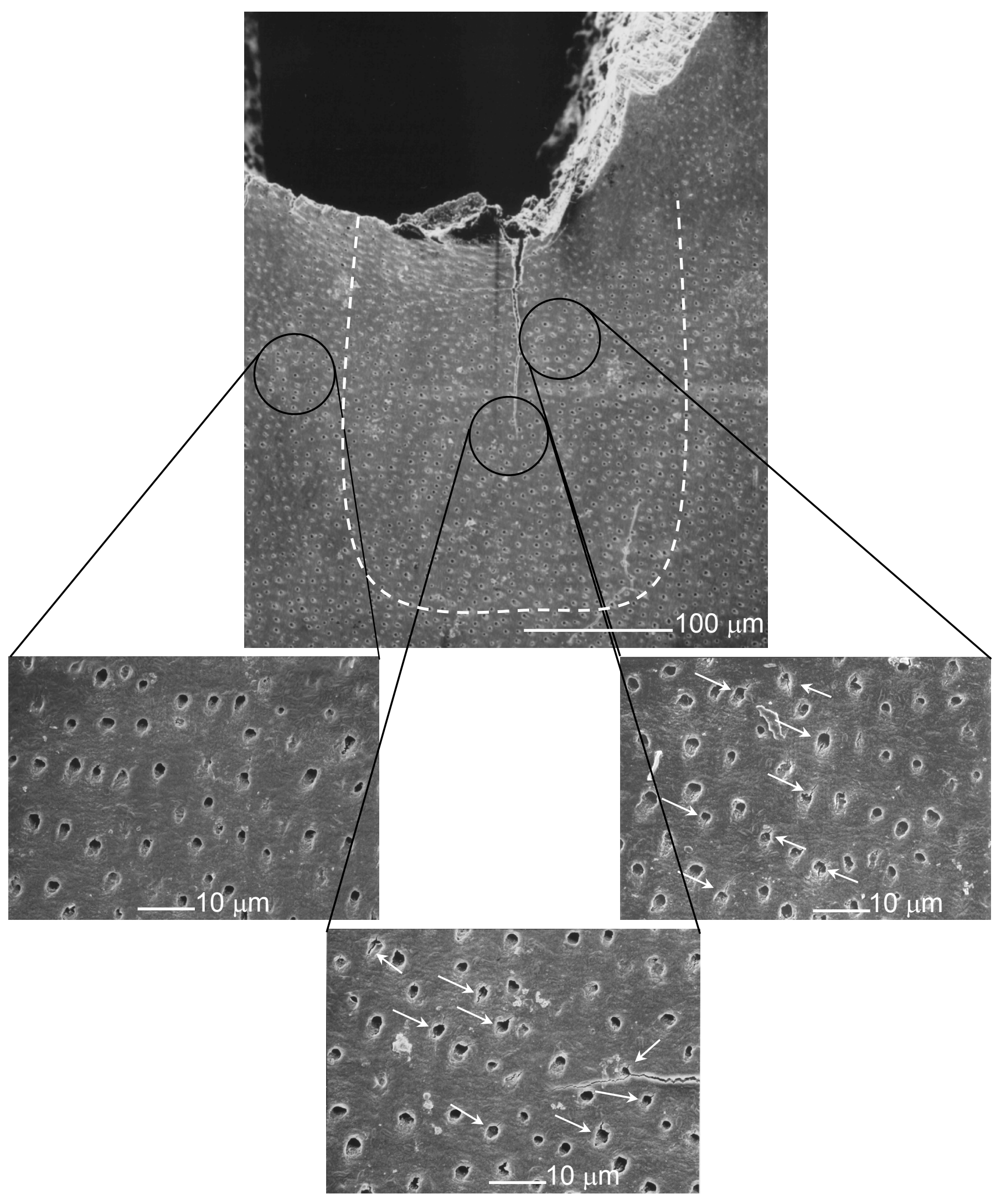


Figure 6: Scanning electron micrographs of the concept of a "yielding" or "damage" zone is shown, based on the regions where the peritubular cuffs are cracked. (a) An overview of a crack emanating from a notch, with the nominal damage zone indicated as a dotted line based on the continuum solution for the "plastic-zone" size (see text), and high magnification micrographs of areas (b) outside the zone, (c) inside the zone and (d) at the notch tip. Note the extensive cracking of peritubular cuffs in the "damage zone" in (c) and (d) (indicated by white arrows). 

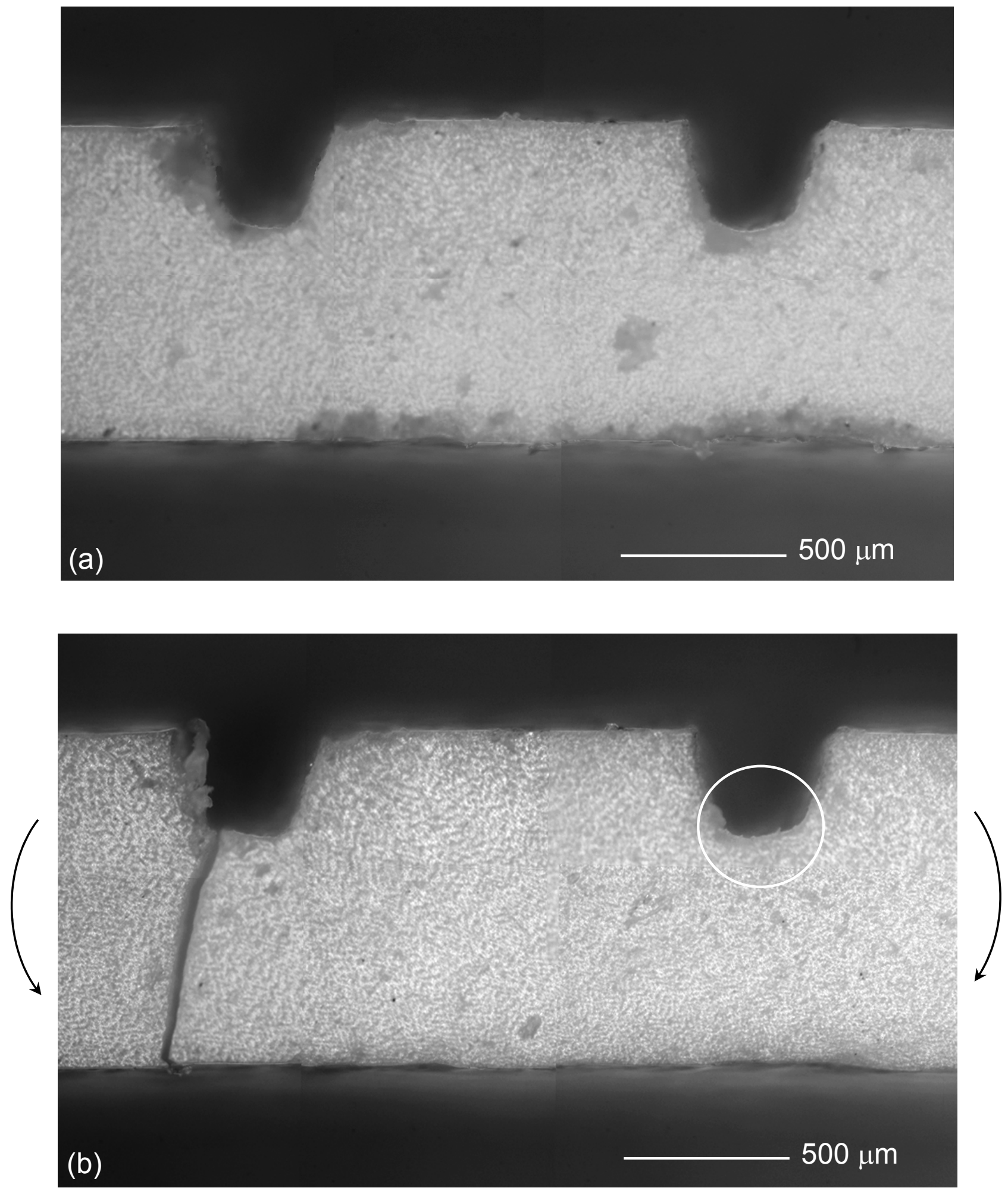

Figure 7: Optical microscope images of the double-notched four-point bend specimen (a) before, and (b) after fracture. The critical area of interest, indicated by the white circle in (b), is in the region beneath the unbroken notch. 


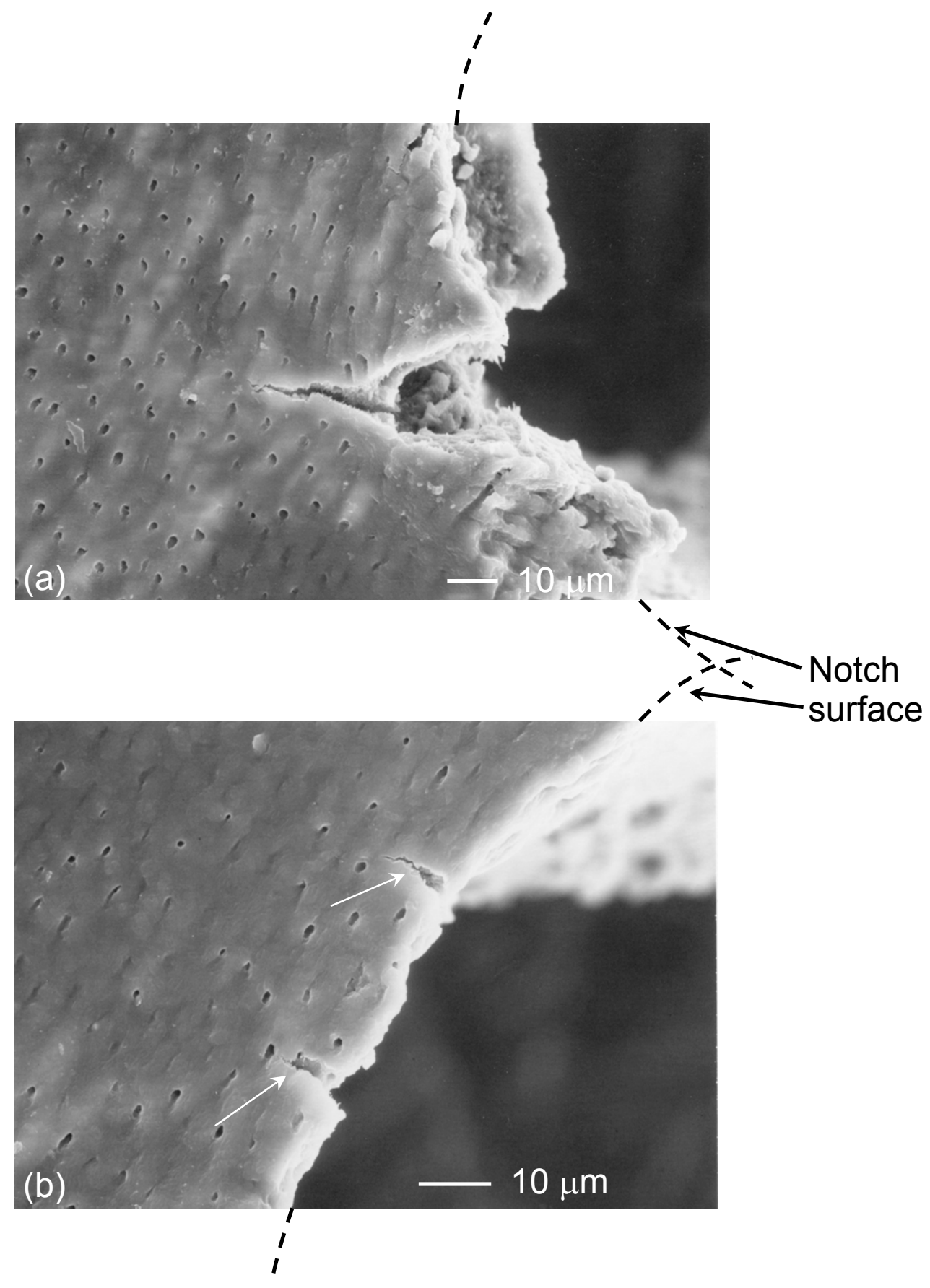

Figure 8: Scanning electron micrographs of the microscopic cracking events immediately prior to unstable fracture in a double-notched four-point bend test, showing micron-scale cracks emerging from the root of the unbroken notch. Multiple initiation sites are evident in (b). The fact that these precursor cracks form at the notch, as opposed to a few hundred micrometers ahead of it, is definitive proof that fracture in dentin is locally strain-controlled. 


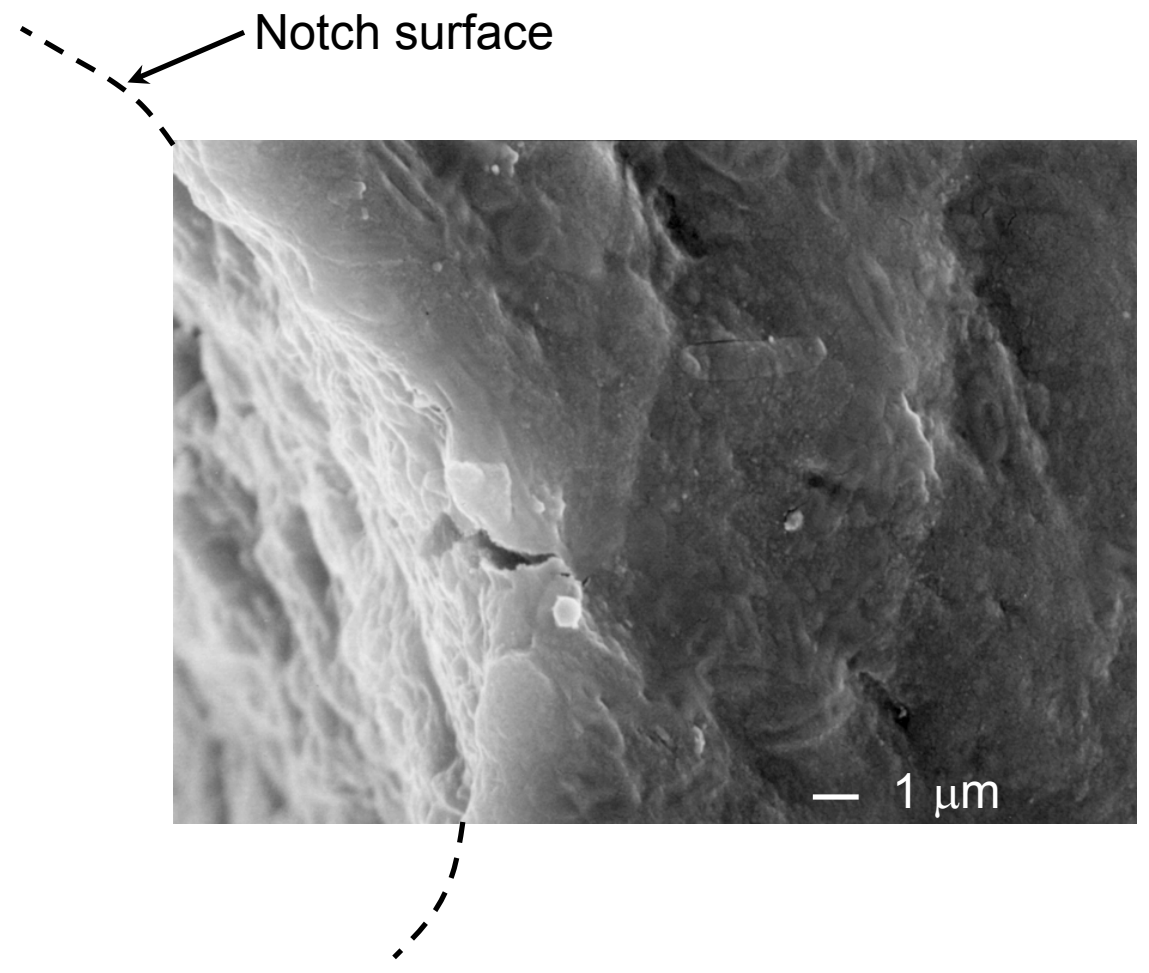

Figure 9: A scanning electron micrograph of a 1-2 $\mu \mathrm{m}$ precursor crack initiating at the root of the unbroken notch in a double-notched four-point bend test. 

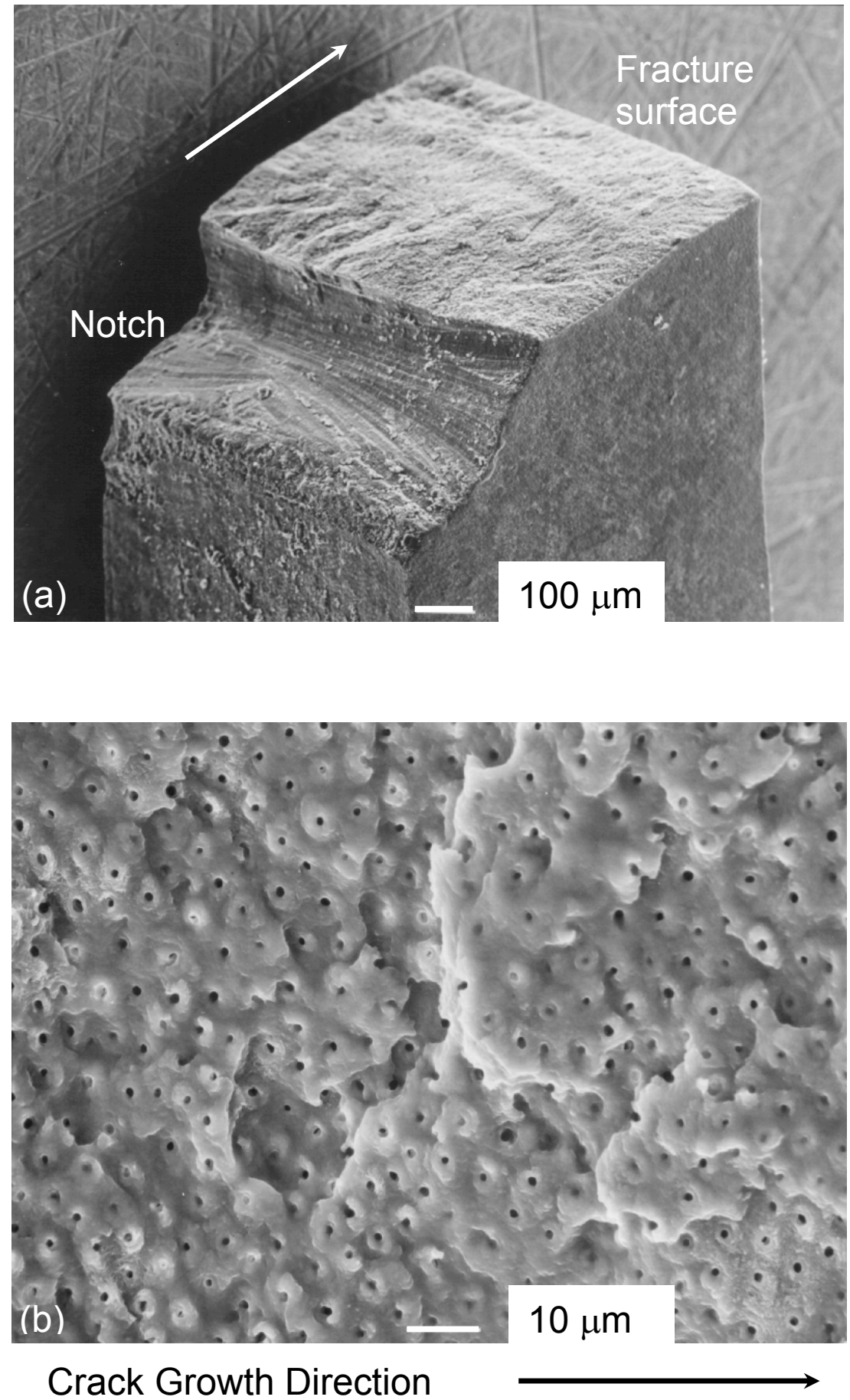

Figure 10: (a) A low-magnification scanning electron micrograph of the broken notch in a double-notched four-point bend test. The white arrow indicates the nominal direction of crack growth. (b) A high-magnification scanning electron micrograph of the morphology of the resulting fracture surface. 


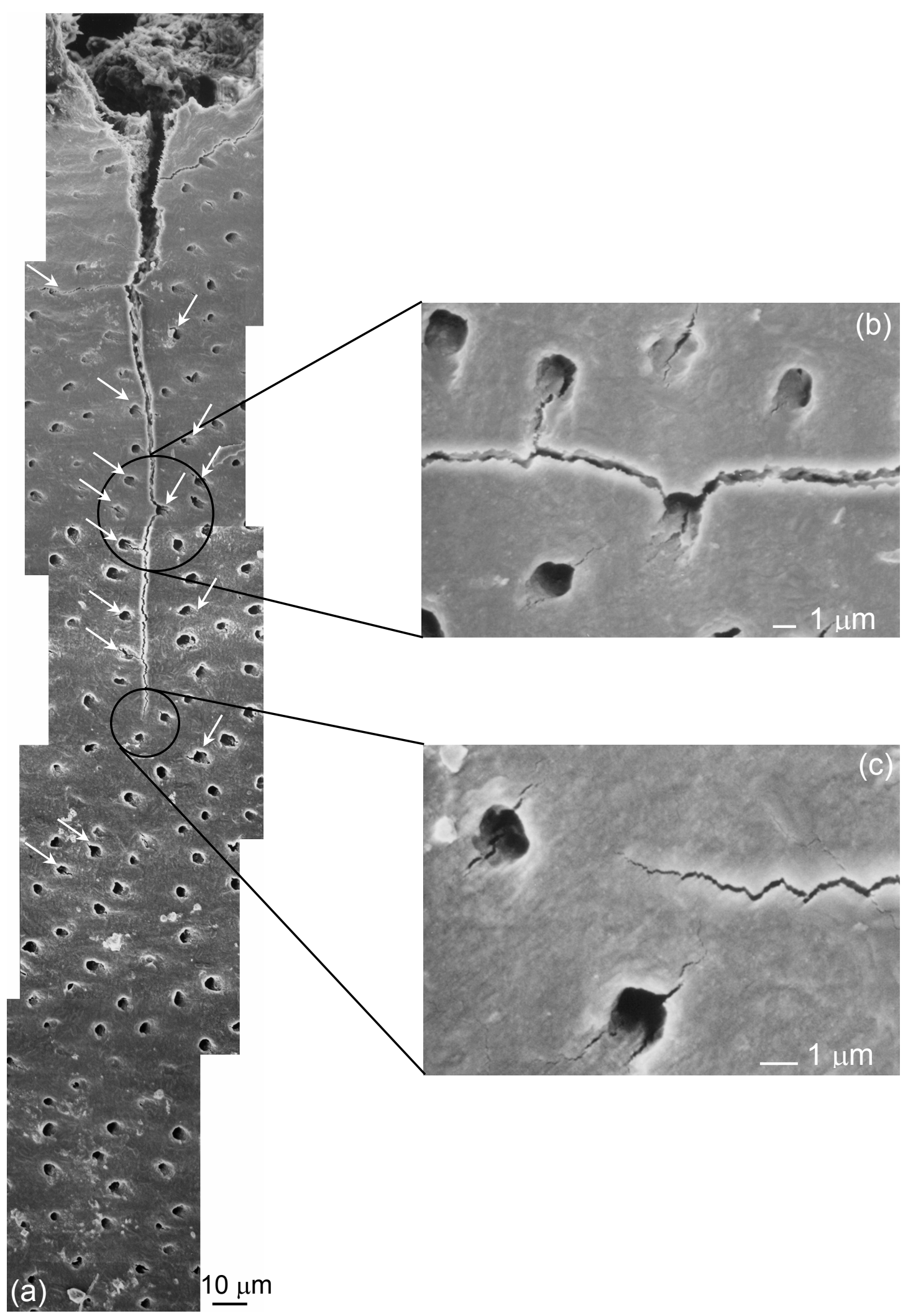

Figure 11: Scanning electron micrographs of a $\sim 200 \mu \mathrm{m}$ crack emanating from the notch, showing the relationship between the crack path with the salient microstructural features. Insets in (b) and (c) show higher magnification images of the cracking of the peritubular cuffs (also shown by the white arrows in (a)) and the interaction of the sub-cracks with the main crack path. 

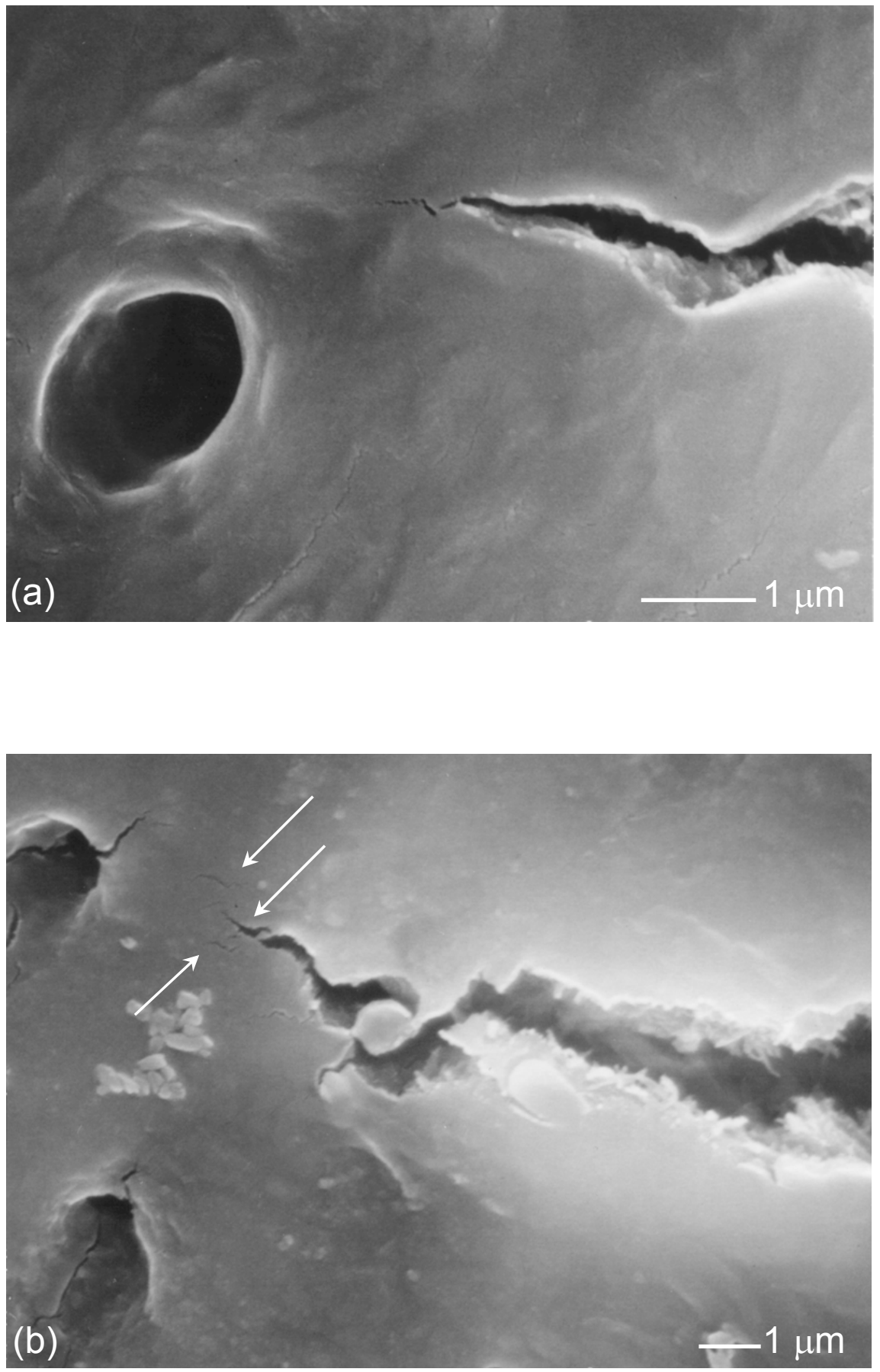

Figure 12: High-magnification scanning electron micrographs of the specific interaction of the tip of the main crack with (a) a tubule and (b) region of microdamage (indicated by white arrows) ahead of a crack tip. 